\title{
Biotecnologías aplicables al desarrollo de algunas especies de Caricáceas cultivadas en la región Andina: avances y problemas
}

\section{Biotechnologies applicable to the development of some Caricaceae species cultivated in the Andean Region: advances and problems}
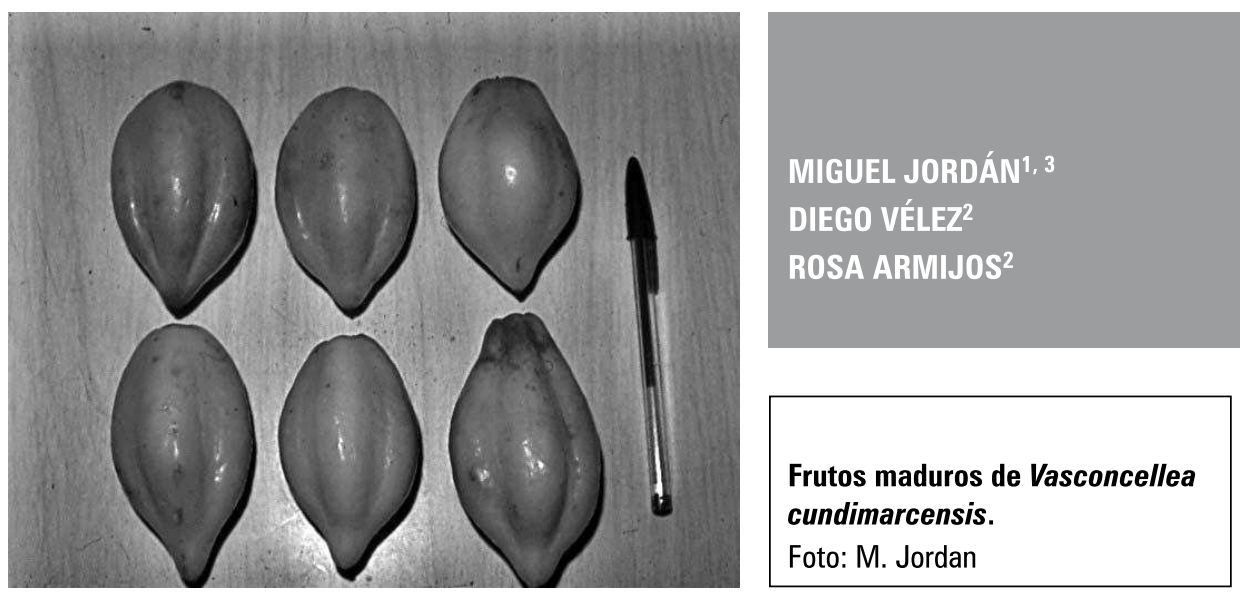

\section{RESUMEN}

Diferentes especies de la Familia Caricaceae corresponden a cultivos importantes de la región Andina, teniendo usos como frutales, producción de compuestos enzimáticos con acción proteolítica, como fuentes de germoplasma y potencial génico de interés posible de usar en programas de mejoramiento. Entre ellas se destacan Carica papaya y otro grupo de cultivos clasificados dentro del género Vasconcellea; entre ellos $V$. cundinamarcensis [sin. C. pubescens] (papayo de montaña); y V. stipulata; ambas portadoras de genes que confieren resistencia a "papaya ringspot virus", así como para tolerancia de frío, con características organolépticas y como patrones de injerto de otro cultivo como es $V$. $x$ heilbornii nm. pentagona (babaco). Según cada cultivo, se evidencian diferentes potenciales regenerativos, ya sea a nivel sexual y asexual, pero también grandes limitaciones que afectan su desarrollo y su regeneración. Algunas de las varias limitaciones específicas a mencionar, según especie, corresponden a problemas de germinación por causa de dormancia influenciada por la testa, variabilidad en el grado de viabilidad según proveniencia y lento desarrollo de postemergencia ( $V$. stipulata). En otras situaciones, la reproducción asexual es obligatoria, tratándose de híbridos interespecíficos estériles, como es el caso de V. $\mathrm{x}$ heilbornii, respuesta que se ve parcialmente limitada. Fundamentalmente la presencia de virosis es el mayor problema que afecta los cultivos comerciales de C. papaya; conjuntamente la existencia de las diferentes formas sexuales limita la productividad de $V$. cundinamarcensis. El objeto del presente trabajo es señalar algunos resultados de estudios conducidos en nuestros laboratorios, así como enfocar algunas estrategias biotecnológicas que han sido exploradas y en desarrollo, útiles en la superación de algunas de dichas problemáticas.

Instituto de Biotecnología, Universidad Mayor, Santiago de Chile.

Instituto de Ecología, Universidad Técnica Particular de Loja, Loja, Ecuador.

Autor para correspondencia.miguel.jordan@umayor.cl 


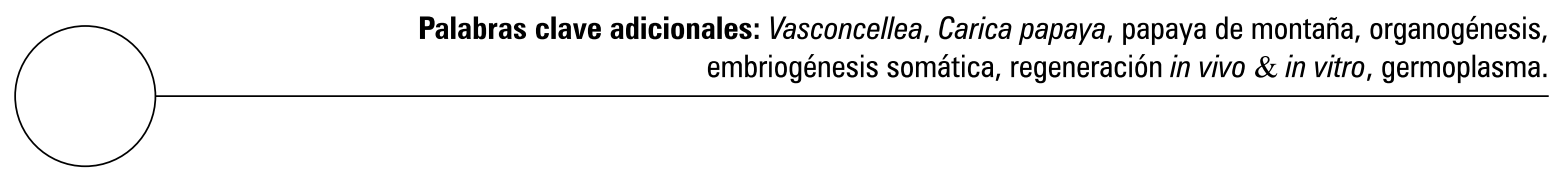

\section{ABSTRACT}

Different species of Caricaceae family are intensively cultivated in the Andean Region consumed as fruit, used as sources of proteolytic enzymatic compounds and as germplasm sources, and have genetic potential of possible interest for improvement programs. Among these species stay Carica papaya and another group of species classified within the Vasconcellea genus, such as $V$. cundinamarcensis [syn. C. pubescens] (mountain papaya) and V. stipulata. Both species carry genes conferring resistance to "papaya ringspot virus" as well as cold tolerance and also have specific organoleptic characteristics. They can be used as graft stocks for other cultures such as V. $x$ heilbornii $\mathrm{nm}$. pentagona (babaco). Different regenerative potentials are evidenced, according to each species at the sexual or asexual level as well as important limitations affecting their development and regeneration. Some of the specific limitations to be mentioned are: germination problems due to dormancy influenced by the testa, variability in the degree of viability according to provenance, slow post-emergence development and associated aspects, with significant losses to fungal attack ( $V$. stipulata). Asexual reproduction is otherwise mandatory, for sterile interspecific hybrids such as $\mathrm{V}$. $\mathrm{x}$ heilbornii, whose response is partially limited. The presence of virosis is the main problem affecting commercial cultures of $C$. papaya; the existence of different sexual forms affects the productivity of $V$. cundinamarcensis. The objective of this work is to mention several results of studies carried out in our laboratories, focusing on various biotechnological strategies already explored or being developed, which can be used to overcome some regeneration problems.

Additional key words: Vasconcellea, Carica papaya, mountain papaya, organogenesis, somatic embryogenesis, in vivo \& in vitro regeneration, germplasm.

Fecha de recepción: 28-04-2009

Aprobado para publicación: 01-06-2009

Lista de abreviaciones: AIA: ácido indolacético; AIB: ácido indol-3-butírico; $\mathrm{AG}_{3}$ : ácido giberélico; ANA: ácido $\alpha$-naftalenacético; BAP: 6-bencilaminopurina; TDZ- 1-fenil-3-(1,2,3,-tidiazol-5-il)urea (tidiazuron).

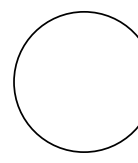

INTRODUCCIÓN

La Región Andina, centro de origen de las numerosas especies e híbridos pertenecientes a la Familia Caricaceae, y que evidencian considerable variabilidad genética, constituyen una fuente importante de recursos genéticos para mejoramiento vegetal y productos tanto agrícolas, medicinales o industriales. Diferentes especies que proveen de características de resistencia a virosis pueden participar en cruzamientos interespecífi- cos generando híbridos, aportar genes de tolerancia para el frío favoreciendo la extensión de cultivos a zonas por hoy limitantes o para otorgar características organolépticas. La recombinación genética, los aspectos de selección y generación de genotipos y la multiplicación, en sus formas, agámica y sexual, vía in vivo o in vitro son en su conjunto todas relevantes. Diferentes potencialidades biotecnológicas han sido exploradas en las 
diferentes especies de Caricáceas y han conducido al conocimiento del potencial morfogénico y regenerativo existente. En el presente trabajo se intenta recopilar algunos antecedentes sobre el potencial de respuestas inductivas y regenerativas inducidas, expresables en células, tejidos y órganos de algunas Caricáceas, biotecnologías de posible utilidad en estudios atingentes a estas especies.

\section{MATERIAL Y MÉTODOS}

A fin de evaluar el potencial morfogénico y regenerativo in vivo e in vitro según la especie, se evaluaron respuestas bajo diferentes condiciones a partir de células y protoplastos derivados, de varios tipos de tejidos y órganos. Se ensayaron anteras a fin de conocer el potencial androgénico existente en microsporas. A partir de suspensiones celulares se evaluó la capacidad de iniciar embriogénesis somática; embriogénesis somática adventicia y producción de semillas sintéticas mediante encapsulación, y en protoplastos la posibilidad de fusiones interespecíficas. A partir de hojas se evaluó la inducción de nuevos brotes o embriogénesis somática, así como desde hipocótilos, ápices caulinares, yemas axilares-secciones nodales y secciones de tallo. Respuestas fisiológicas y adaptativas fueron referidas a aspectos de viabilidad, germinación y control de la hiperhidricidad y caracterización parcial de germoplasma. La metodología empleada se encuentra resumida en Jordan et al. (1986); Jordan (1992); Jordan y Velozo (1996); Jordan y Piwanski (1999) y Vélez et al. (2009).

\section{RESULTADOS Y DISCUSIÓN}

Respuestas morfogénicas y regenerativas del material estudiado, parcial caracterización del germoplasma ( $V$. cundinamarcensis), condiciones de cultivo y de requerimientos hormonales se resumen en las tablas 1 y 2 . De los resultados se desprende que una gran parte de los diferentes tipos de explantes ensayados expresan respuestas morfogénicas dependientes de las potencialidades inherentes a la especie y del órgano-tejido examinado, aun en presencia de niveles de reguladores de crecimiento y condiciones de cultivo muy semejantes. Así, por ejemplo, la inducción de embriones somáticos en callo de diferente origen $V$. cundinamarcensis es fácilmente inducible (Jordan, 1992), mientras que en $V$. heilbornii nm. pentagona este tejido prospera difícilmente, aun en presencia de addenda orgánica, evidenciando pardeamiento sin generar embriones; respuesta en parte semejante a nuestros resultados con $C$. papaya. Por el contrario, explantes de lámina foliar de $V$. cundinamarcensis no son inducibles a expresar la formación de brotes de-novo, mientras sí se inician en hojas adultas de babaco (Jordan y Piwanski, 1997, 1999).

V. cundimamarcensis expresa amplia respuesta morfogénica en sus tejidos. Diferentes tipos y niveles hormonales (combinaciones de ANA con BA; ANA con Z; ANA con K; AIA con BA y AIA con $Z$ ) inician todos la formación de embriones en callo derivados de temas axilares de plantas adultas o de hipocótilos (Jordan, 1986). Dichos embriones son inducibles, además de generar embriones adventicios, con lo cual se facilita su multiplicación masiva (Jordan y Velozo, 1996). Un encapsulamiento de estos embriones (para uso como semilla sintética) también parece factible (Jordan, 2005).

Dadas las variadas formas sexuales (por ejemplo en $V$. cundinamarcensis poco reconocibles en material juvenil), estrategias como la inducción homozigosis de doble haploides mediante el proceso de androgénesis en plantas altamente productivas aparece como una estrategia de selección y producción de germoplasma en programas de mejoramiento genético. Si bien las respuestas androgénicas en Caricáceas han sido poco descritas, en estudios preliminares el potencial en $V$. cundimarcensis, alcanza a aprox. $>5 \%$ de inducción de embrioides derivados de polen y hasta un 91\% de callo embriogénico, probablemente también de carácter haploide (Jordan, 1996). 
El potencial de cruzamientos interespecíficos entre especies de la familia Caricaceae está ampliamente establecido, y con ello su potencial de recombinación (con resultados tan notables como en babaco). Al respecto, Kyndt et al. (2005 $\mathrm{a}, \mathrm{b})$ indica que la hibridación es común entre especies del genero Vasconcellea, encontrándose signos de introgresión de $V$. cundinamarcensis en $V$. stipulata en condiciones naturales como controladas (De Zerpa, 1980); dicha variabilidad es notable en $V$. stipulata en material colectado de diferentes procedencias (Horovitz y Jiménez, 1967). Al respecto, cabe notar que en las poblaciones de cultivo de $V$. cundinamarcensis, originarias de las regiones de altura de la Region Andina, distribuida desde Panamá a Bolivia en zonas temperadas entre 1.500-3.000 m (Badillo, 1971; Muñoz, 1965), adaptadas a la zona costera en Chile central ( $28^{\circ}$ y $36^{\circ} \mathrm{S}$.), éstas parecen ser más bien homogéneas; estudios isoenzimáticos denotan extrema similitud en muestras en más de $1.000 \mathrm{~km}$ de extensión.

Así, considerando el potencial de cruzamiento interespecies existente, trabajos experimentales de fusión a nivel de protoplastos han sido sin embargo bastante limitados. Al respecto, algunos experimentos de fusiones de protoplastos entre $V$. cundinamarcensis y $C$. papaya con perspectivas de lograr híbridos o recombinantes con caracteristicas de interés posibles de usar en programas genéticos (inserción de resistencia a PRV, características de tolerancia al frío, generación de recombinantes como patrones de injerto), sólo inician las primeras fases de desarrollo embriogénico in vitro y no desarrollan estructuras viables (Jordan et al., 1986). La imcompatibilidad génica al recombinar el genoma de ambas procedencias es probablemente la causa de los escasos resultados disponibles. Sin embargo, establecidos los mecanismos morfogénicos y de regeneración celular y tisular y con el advenimiento de metodologías que permiten la inserción de genes foráneos entre una especie y otra permite la fijación y expresión de características particulares deseables. Entre éstas, ayudan marcadores moleculares ligados a genes de resistencia a PRV presentes en $V$. cundinamarcensis (Dillon et al., 2006). Finalmente, mediante ingeniería genética, insertando el gene codificante de la proteina viral del PRV, ha sido posible obtener existosamente plantas transgénicas de C. papaya resistentes en variedades comerciales, intensidad de respuesta que depende de la dosificación presente de dicho gen en las nuevas plantas transformadas (Fitch et al., 1992; Tennant et al., 1994, 2001.; Gonzalves y Ferreira, 2003). Otros muchos mecanismos de regulación son necesarios en la estabilización de respuestas ante la modificación genética y consecución final de un producto transgénico comercial. Entre las Caricaeas, las respuestas regenerativas in vitro, según el caso, parecen ser más satisfactorias que en muchas especies vegetales de carácter recalcitrante, característica de no menor relevancia cuando a nivel del material celular transformado los procesos morfogénicos deben encaminarse hacia la obtención in vitro de una planta viable completa.

Tabla 1. Resumen de respuestas regenerativas, potencial regenerativo y parcial caracterización del germoplasma en algunas Caricáceas*.

\begin{tabular}{|c|c|c|c|c|}
\hline Especie-explante & $\begin{array}{l}\text { Vasconcellea } \\
\text { cundimarcensis }\end{array}$ & $\begin{array}{c}\text { V. heilbornit nm. } \\
\text { pentagona }\end{array}$ & V. stipulata & $\begin{array}{l}\text { Carica } \\
\text { papaya }\end{array}$ \\
\hline $\begin{array}{l}\text { Microsporas } \\
\text { uninucleadas }\end{array}$ & $\begin{array}{l}\text { Androgénesis, } \\
\text { embriones somáticos } \\
\text { derivados de } \\
\text { polen-callo }\end{array}$ & (No aplica) & & \\
\hline Cultivos celulares & $\begin{array}{l}\text { Embriones } \\
\text { somáticos, plántulas, } \\
\text { embriogénesis; } \\
\text { embriog. adventicia, } \\
\text { encapsulación }\end{array}$ & Formación de callo & Formación de callo & Formación de callo \\
\hline
\end{tabular}


Tabla 1. Continuación

\begin{tabular}{|c|c|c|c|c|}
\hline Especie-explante & $\begin{array}{l}\text { Vasconcellea } \\
\text { cundimarcensis }\end{array}$ & $\begin{array}{l}\text { V. heilbornit nm. } \\
\text { pentagona }\end{array}$ & V. stipulata & $\begin{array}{l}\text { Carica } \\
\text { papaya }\end{array}$ \\
\hline $\begin{array}{l}\text { Fusión de } \\
\text { protoplastos }\end{array}$ & $\begin{array}{l}\text { Con Carica papaya; } \\
\text { primeros estados de } \\
\text { embriogénesis de } \\
\text { células fusionadas }\end{array}$ & & & $\begin{array}{l}\text { Con Vasconcellea. } \\
\text { cundinamarcensis; } \\
\text { primeros estados de } \\
\text { embriogénesis de } \\
\text { células fusionadas }\end{array}$ \\
\hline Lámina foliar & $\begin{array}{l}\text { Sin respuesta } \\
\text { morfogénica }\end{array}$ & $\begin{array}{l}\text { Formación de callo, } \\
\text { brotes de novo o } \\
\text { embriones somáticos, } \\
\text { hoja adulta }\end{array}$ & $\begin{array}{l}\text { Iniciación de brotes } \\
\text { de hojas derivadas } \\
\text { de ejes embrionarios }\end{array}$ & \\
\hline $\begin{array}{l}\text { Elemento bulboso } \\
\text { en porción basal de } \\
\text { lámina foliar }\end{array}$ & & $\begin{array}{l}\text { Inducción de nuevos } \\
\text { brotes; plántulas }\end{array}$ & $\begin{array}{l}\text { (Estructura visible } \\
\text { poco desarrollada } \\
\text { según ontogenia } \\
\text { foliar) }\end{array}$ & \\
\hline Hipocótilo & $\begin{array}{l}\text { Embriogénesis } \\
\text { somática }\end{array}$ & (No aplica) & $\begin{array}{l}\text { Regeneración de } \\
\text { plántulas, control de } \\
\text { la hiperhidricidad }\end{array}$ & Formación de callo \\
\hline Ápices caulinares & & $\begin{array}{l}\text { A partir de subcultivo } \\
\text { de los nuevos bro- } \\
\text { tes generados del } \\
\text { elemento bulboso que } \\
\text { evidencian inducción } \\
\text { de raíces, regeneración } \\
\text { de plántulas }\end{array}$ & & $\begin{array}{l}\text { Formación de } \\
\text { callo de ápices } \\
\text { de plántulas en } \\
\text { desarrollo }\end{array}$ \\
\hline $\begin{array}{l}\text { Yemas axilares- } \\
\text { secciones nodales }\end{array}$ & $\begin{array}{l}\text { Brotación de las yemas } \\
\text { axilares preexistentes; } \\
\text { formación nuevos } \\
\text { brotes múltiples, } \\
\text { callo y embriogénesis } \\
\text { indirecta }\end{array}$ & $\begin{array}{l}\text { Formación de raíces y } \\
\text { plantas escasa }\end{array}$ & $\begin{array}{l}\text { Brotación de las } \\
\text { yemas axilares } \\
\text { preexistentes; } \\
\text { nuevos brotes, callo }\end{array}$ & \\
\hline Estacas de tallo & Raíces; plantas & Raíces; plantas & & \\
\hline Semillas & & (No aplica) & $\begin{array}{l}\text { Escarificación } \\
\text { promueve } \\
\text { porcentaje y } \\
\text { reduce tiempo de } \\
\text { germinación }\end{array}$ & \\
\hline Embriones & $\begin{array}{l}\text { Incremento en } \\
\text { el porcentaje de } \\
\text { germinación in vitro en } \\
\text { presencia de ANA y } \\
\text { Kin, medio MS }\end{array}$ & (No aplica) & $\begin{array}{l}\text { Reducción tiempo } \\
\text { de latencia }\end{array}$ & \\
\hline \multicolumn{5}{|c|}{ Caracterización de germoplasma } \\
\hline $\begin{array}{l}\text { Formas sexuales en } \\
\text { plantas masculinas } \\
\text { y productoras } \\
\text { femeninas }\end{array}$ & $\begin{array}{l}\text { 1. Determinación de } \\
\text { extractos de fenoles } \\
\text { HPLC de hojas y flores } \\
\text { plantas ambos sexos } \\
\text { 2. Electroforesis } \\
\text { SDS poliacrilamida } \\
\text { hojas, flores, pecíolos } \\
\text { en plantas de ambos } \\
\text { sexos }\end{array}$ & & & \\
\hline $\begin{array}{l}\text { Ecotipos-variación } \\
\text { somaclonal }\end{array}$ & $\begin{array}{l}\text { Electroforesis en gel } \\
\text { de isoenzimas (AAT) } \\
\text { y otras enzimas } \\
\text { indicadoras }\end{array}$ & & & \\
\hline
\end{tabular}

\footnotetext{
${ }^{*}$ Resultados experimentales realizados por autores exclusivamente.
} 


\section{Tabla 2. Resumen de mejores condiciones inductoras de respuestas morfogénicas y regenerativas en varias Caricáceas}

\begin{tabular}{|c|c|c|c|c|}
\hline $\begin{array}{l}\text { Respuesta } \\
\text { morfogénica }\end{array}$ & $\begin{array}{c}\text { Inducción } \\
\text { - tratamiento }\end{array}$ & $\begin{array}{l}\text { Medio nutritivo } \\
\text { - reguladores }\end{array}$ & Addenda - otros & Resultado \\
\hline $\begin{array}{l}\text { Androgenesis } \\
\text { (V. } \\
\text { cundinamarcensis) }\end{array}$ & $\begin{array}{l}\text { Cultivo de anteras } \\
\text { y microsporas } \\
\text { uninucleadas de } \\
\text { plantas femeninas }\end{array}$ & $\begin{array}{l}\text { Sales NN; } \\
\text { microelementos de } \\
\mathrm{MS} \text {, sacarosa } 60 \\
\mathrm{~g} \mathrm{~L}^{-1} \text {. } \\
\text { AIA } 1,0 \mathrm{mg} \mathrm{L}^{-1} \\
\text { BAP } 1,0 \mathrm{mg} \mathrm{L}^{-1} \\
\text { (papel Whatman } \mathrm{N}^{\circ} 1 \\
\text { reemplaza agar) }\end{array}$ & $\begin{array}{l}\text { De preferencia cultivo } \\
\text { bajo luz fluorescente } \\
\text { tenue, ciclos de } 18 \\
\text { horas; aprox. } 48 \mu \mathrm{mol} \\
\mathrm{m}^{-2} \mathrm{~s}^{-1}\end{array}$ & $\begin{array}{l}\text { Generación de } \\
\text { embrioides de polen } \\
6,5 \%\end{array}$ \\
\hline $\begin{array}{l}\text { Embriogenesis } \\
\text { somática } \\
\text { [hipocótilo] } \\
\text { (V. } \\
\text { cundinamarcensis; } \\
\text { C. papaya) }\end{array}$ & $\begin{array}{l}\text { Formación de callo } \\
\text { inicial, posteriormente } \\
\text { subcultivo, estático o } \\
\text { agitación cte. }\end{array}$ & $\begin{array}{l}\text { Varios embriones } \\
\text { somáticos, plántulas, } \\
\text { embriogénesis; } \\
\text { embriog. adventicia, } \\
\text { encapsulación }\end{array}$ & $\begin{array}{l}\text { Para el caso de } C \text {. } \\
\text { papaya se requiere } \\
\text { oscuridad. Medios: } \\
\text { MS y NN }\end{array}$ & $\begin{array}{l}\text { En } V \text {. } \\
\text { cundinamarcensis } \\
\text { formación de callo y } \\
\text { embriones somáticos, } \\
\text { tb. embriones } \\
\text { adventicios, } \\
\text { abundantes y } \\
\text { plántulas usando } \\
\text { pretratamientos con } \\
\text { 2,4-D }\end{array}$ \\
\hline $\begin{array}{l}\text { Fusión de } \\
\text { protoplastos } \\
\text { (V. } \\
\text { cundinamarcensis } x \\
\text { C. papaya) }\end{array}$ & $\begin{array}{l}\text { Células de } C \text {. } \\
\text { cundinamarcensi s } \\
\text { derivadas de hoja } \\
\text { juvenil; de C. papaya } \\
\text { obtenidas de callo } \\
\text { formado de hipocótilo }\end{array}$ & $\begin{array}{l}\text { Preplasmólisis con } \\
\text { manitol } 13 \%, 60 \mathrm{~min} \text {; } \\
\text { digestión por } 39 \mathrm{~h} \\
\text { en celulasa }(2 \%) \text {, } \\
\text { Macerozyma R-10 } \\
(0,5 \%) \text { y manitol } 13 \% \text {, } \\
\text { en oscuridad, } 30^{\circ} \mathrm{C} \text {, } \\
\text { sales MS }\end{array}$ & $\begin{array}{l}\text { Desinfección } \\
\text { hoja en etanol } 70 \% \text {, } \\
2 \text { min }\end{array}$ & $\begin{array}{l}\text { Protoplastos viables } \\
\text { de ambos tejidos, } \\
\text { densidad aprox. } \\
44 \times 104 \text { en C. } \\
\text { cundinamarcensis. } \\
\text { Primeros estados } \\
\text { de división y } \\
\text { embriogénesis de } \\
\text { productos de fusión } \\
\text { aunque sin posterior } \\
\text { desarrollo }\end{array}$ \\
\hline $\begin{array}{l}\text { Formación } \\
\text { de embriones } \\
\text { somáticos-brotes } \\
\text { en lámina foliar } \\
\text { (V. heilbornii } \mathrm{nm} \text {. } \\
\text { pentagona) }\end{array}$ & $\begin{array}{l}\text { Inducción de } \\
\text { brotes y embriones } \\
\text { somáticos en } \\
\text { secciones de lamina } \\
\text { foliar; respuestas } \\
\text { de acuerdo a } \\
\text { uso y niveles de } \\
\text { reguladores }\end{array}$ & $\begin{array}{l}\text { Fases de cultivo de } \\
\text { hoja y subcultivo de } \\
\text { callo al inicio con } \\
\text { TDZ y AIA, luego con } \\
\mathrm{AG}_{3} \text {. Callo en placa, } \\
\text { estático desarrolla } \\
\text { embriones somáticos. } \\
\text { En babaco formación } \\
\text { de brotes solo con } \\
\text { alta concentración } \\
\text { de TDZ }\end{array}$ & $\begin{array}{l}\text { Inducción de } \\
\text { embriones somáticos } \\
\text { (indirecto) sólo en } \\
\text { presencia glutamina, } \\
\text { hidrolizado de caseína } \\
\text { y cisteína }\end{array}$ & $\begin{array}{l}\text { Varias fases } \\
\text { de subcultivo; } \\
\text { con respuesta } \\
\text { embriogénica menor } \\
\text { que observada en } V \text {. } \\
\text { cundinamarcensis, en } \\
\text { la cual no se generan } \\
\text { por contrario brotes } \\
\text { a partir de explantes } \\
\text { foliares }\end{array}$ \\
\hline $\begin{array}{l}\text { Formación de brotes } \\
\text { [elemento bulboso] } \\
\text { en lámina foliar } \\
\text { (V. heilbornii } \mathrm{nm} \text {. } \\
\text { pentagona) }\end{array}$ & $\begin{array}{l}\text { Inducción de brotes } \\
\text { sólo del elemento } \\
\text { bulboso, ligado } \\
\text { vascularmente y } \\
\text { cultivado con sección } \\
\text { de hoja }\end{array}$ & $\begin{array}{l}\text { Medio MS con TDZ } \\
\text { solo o combinado } \\
\text { incluyendo hidrolizado } \\
\text { de caseína y sulfato } \\
\text { de adenina. Para } \\
\text { rizogénesis de brotes } \\
\text { en subcultivo AlB } 2,0 \\
\text { mg L }^{-1}\end{array}$ & $\begin{array}{l}\text { Presencia de maltosa } \\
(2 \%) \text { y TDZ 3,0 mg } \\
\mathrm{L}^{-1} \text { imprescindibles } \\
\text { para la inducción de } \\
\text { respuesta y síntesis } \\
\text { de clorofila en los } \\
\text { nuevos brotes }\end{array}$ & $\begin{array}{l}\text { Obtenidos los brotes } \\
\text { el enraizamiento en } \\
\text { subcultivo ocurre en } \\
\text { un } 50 \% \text { aprox. }\end{array}$ \\
\hline
\end{tabular}


Tabla 2. Continuación.

\begin{tabular}{|c|c|c|c|c|}
\hline $\begin{array}{l}\text { Respuesta } \\
\text { morfogénica }\end{array}$ & $\begin{array}{l}\text { Inducción } \\
\text { - tratamiento }\end{array}$ & $\begin{array}{l}\text { Medio nutritivo } \\
\text { - reguladores }\end{array}$ & Addenda - otros & Resultado \\
\hline $\begin{array}{l}\text { Ápices caulinares } \\
\text { [regenerados in } \\
\text { vitro]. } \\
\text { (V. heilbornii nm. } \\
\text { pentagona) }\end{array}$ & Formación de callo & & & $\begin{array}{l}\text { A partir de nuevos } \\
\text { brotes in vitro, } \\
\text { formación de callo, } \\
\text { inducción de raíces, } \\
\text { plántulas }\end{array}$ \\
\hline $\begin{array}{l}\text { Yemas axilares } \\
\text { (V. heilbornii } \mathrm{nm} \text {. } \\
\text { pentagona; V. } \\
\text { cundinamarcensis; } \\
\text { C. papaya; V. } \\
\text { stipulata) }\end{array}$ & $\begin{array}{l}\text { Inducción de callo } \\
\text { morfogénico en } \\
\text { porción proximal } \\
\text { del ápice en varias } \\
\text { especies conducente } \\
\text { a embriones } \\
\text { somáticos en } \\
\text { subcultivo }\end{array}$ & $\begin{array}{l}\text { En babaco, inducción } \\
\text { raíces en presencia } \\
\text { de ANA 0,01 mg } \\
\mathrm{L}^{-1} \text { y BAP } 0,8 \mathrm{mg} \\
\mathrm{L}^{-1} \text {. Nutrientes NN. } \\
\text { Para C. papaya, V. } \\
\text { cundinamarcenesis y } \\
V \text {. stipulata (secciones } \\
\text { nodales), brotación } \\
\text { de yemas axilares; } \\
\text { con formación de } \\
\text { nuevos brotes, } \\
\text { brotes múltiples, } \\
\text { callo y embriogénesis } \\
\text { indirecta }\end{array}$ & $\begin{array}{l}\text { Babaco requiere } \\
\text { incluir junto a } \\
\text { reguladores carbón } \\
\text { activado } 0,6 \mathrm{~g} \mathrm{~L}^{-1} \text {; } \\
\text { tb. AdS, hidrolizado } \\
\text { caseína y cisteína } \\
\text { a fin de evitar } \\
\text { pardeamiento. } \\
\text { Medios WPM y MS }\end{array}$ & $\begin{array}{l}\text { En babaco, inducción } \\
\text { de raíces en la base } \\
\text { con producción de } \\
\text { plantas en forma } \\
\text { errática }\end{array}$ \\
\hline $\begin{array}{l}\text { Estacas de tallo } \\
\text { (V. heilbornii } \mathrm{nm} \text {. } \\
\text { pentagona) }\end{array}$ & $\begin{array}{l}\text { Tratamiento directo } \\
\text { de inmersión y } \\
\text { posterior mantención } \\
\text { de estacas en agua } \\
\text { conteniendo AIB }\end{array}$ & $\begin{array}{l}\text { Formación de raíces } \\
\text { en presencia de AlB, } \\
50 \mathrm{mg} \mathrm{L}^{-1}, 7 \mathrm{~min}\end{array}$ & $\begin{array}{l}\text { Addenda no requiere; } \\
\text { solo condiciones } \\
\text { de invernadero. } \\
\text { Respuesta a luz }\end{array}$ & $\begin{array}{l}\text { Todas las estacas } \\
\text { con 3-4 raíces en la } \\
\text { porción proximal }\end{array}$ \\
\hline $\begin{array}{l}\text { Semillas } \\
\text { (V. stipulata) }\end{array}$ & $\begin{array}{l}\text { Escarificación de la } \\
\text { esclerotesta }\end{array}$ & Peróxido de hidrógeno & (no aplica) & $\begin{array}{l}\text { Incremento de } \\
\text { porcentaje de } \\
\text { germinación de } 0,5 \% \\
\text { a aprox. } 53 \% \text { en } 40 \\
\text { días }\end{array}$ \\
\hline $\begin{array}{l}\text { Embriones } \\
\text { (V. stipulata) }\end{array}$ & $\begin{array}{l}\text { Ruptura de la } \\
\text { dormancia, } \\
\text { desarrollo rápido eje } \\
\text { embrionario }\end{array}$ & $\begin{array}{l}\text { Ajuste concentración } \\
\text { de sales MS y NN } \\
\text { más } \mathrm{AG}_{3}\end{array}$ & (no aplica) & $\begin{array}{l}\text { Germinación más } \\
\text { temprana, control } \\
\text { de hiperhidricidad de } \\
\text { ejes embrionarios en } \\
\text { desarrollo; reducción } \\
\text { al } 0-13 \%\end{array}$ \\
\hline
\end{tabular}

MS: Murashige y Skoog, 1962; NN: Nitsch y Nitsch, 1969; WPM: Lloyd y McCown, 1981.

\section{CONCLUSIONES}

Con base en la vasta literatura existente, varias especies adscritas a la familia de la literatura existente, sometidas a condiciones inductivas específicas in vivo e in vitro, parecen expresar un po- tencial embriogénico y regenerativo satisfactorio a nivel celular, tisular o de órganos. Lo anterior es ventajoso en programas de mejoramiento o de propagación masiva para fines productivos. Particularmente relevante, considerando estrategias como las de transgenia, es la posibilidad de poder ser regeneradas plantas viables llevando íntegra- 
mente el gen-carácter de interés a partir de células o tejidos virtualmente transformados. En segundo lugar, la posibilidad de poder seleccionar material de interés y la regeneración de plantas a partir del nivel celular hace posible y facilita también la selección temprana de características particulares, naturales o inducidas detectables a ese nivel y, en tercer lugar, la expresión de la androgénesis, derivando en la regeneración de plantas di-haploides (doble haploides o de carácter homocigoto) derivadas del polen, respuesta inducible y obtenible a corto plazo, en una sola generación, permite igualmente la selección de material con características no posibles de ser obtenidas en programas de mejoramiento convencionales. La obtención de plantas en forma directa a partir del polen descarta la fase de generación de heterocigotos predominantes en las primeras fases de cruzamientos convencionales. La resultante del empleo conjunto de las biotecnologías mencionadas implica poder incrementar en el ámbito de las Caricaeas la variabilidad de germoplasma por hoy disponible y hacer uso de éste en futuros programas de selección, recombinación o de mejoramiento genético en las especies adscritas a esta familia de plantas.

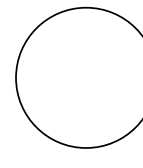

Badillo, V.M. 1971. Monografía de la familia Caricaceae. Fac. Agr. Maracay, Venezuela.

De Zerpa, D.M. 1980. Comportamiento meiótico de la descendencia híbrida producida al transferir el carácter bisexual de Carica pubescens a Carica stipulata. Rev. Fac. Agron. (Maracay) 11, 5-47.

Dillon, S.; C. Ramage; S. Ashmore y R.A. Drew. 2006. Development of a codominant CAPS marker linked to PRSV-P resistance in highland papaya. Theor. Appl. Genet. 113, 1159-1169.

Fitch, M.; R. Manshardt; D. Gonsalves; J. Slightom y J. Sanford. 1992. Virus resistant papaya derived from tissues bombarded with the coat protein gene of papaya ringspot virus. BioTechnol. 10, 1466-1472.

Gonsalves, D. y S. Ferreira. 2003. Transgenic papaya: A case for managing risks of papaya ringspot virus in Hawaii. Online. Plant Health Progress doi:10.1094/ PHP-2003-1113-03-RV.

Horovitz S. y H. Jiménez. 1967. Cruzamientos interespecíficos e intergenéricos en Caricáceas y sus implicaciones fitotécnicas. Agronomía Tropical (Maracay) $17,323-343$.

Jordan, M.; G. Ciudad; M.L. Rojas y F. Valverde. 1986. Isolation, culture and fusion of Carica candamar-

\section{REFERENCIAS BIBLIOGRÁFICAS}

censis and C. papaya protoplasts. Gartenbauwissenschaft 51, 175-178.

Jordan, M. 1992. Capítulo II 12: Micropropagation of Papaya (Carica sp). pp. 418-459. En: Bajaj, Y.P.S. (ed.) Biotechnology in Agriculture and Forestry Vol. 18, Springer-Verlag, Berlin-Heidelberg.

Jordan, M. 1996. In vitro regeneration of some little known Andean fruit crops. p. 34. Proc. 1st. Conference on Fruit Production in the Tropics and Subtropics. Humboldt-Universität zu Berlin, Berlin.

Jordan, M. y J. Velozo. 1996. Improvement of somatic embryogenesis in highland-papaya cell suspensions. Plant Cell Tissue Organ Cult. 44, 189-194.

Jordan, M. y D. Piwanski. 1997. Regeneration of babaco [Carica pentagona (Heilborn) Badillo] using leaf explants and shoot-tip culture. Rev. Intl. Bot. Exp. 61, 109-115.

Jordan, M. y D. Piwanski. 1999. Regeneration of babaco (Carica pentagona) through somatic embryogenesis. Фyton 64, 101-105.

Jordan, M. 2005. Capítulo 4: Aplicaciones de la técnica de cultivo de tejidos. pp.73-98. En: Prieto, H., M. Jordan; L.P. Barrueto; M.C. Rocha y D. Durzan. Biotecnologia vegetal. Colección Libros INIA, No 15. 
Instituto de Investigaciones Agropecuarias, Ministerio de Agricultura, Prograf Impresores, Santiago.

Kyndt, T.; E. Romeijn-Peeters; B. Van Droogenbroeck; J. Romero-Motochi; G. Gheysen y P. Goetghebeur. 2005a. Species relationships in the genus Vasconcellea (Caricaceae) based on molecular and morphological evidence. Amer. J. Bot. 92, 1033-1044.

Kyndt, T.; B. Van Droogenbroeck; E. Romeijn-Peeters; J. Romero-Motochi; X. Scheldeman; P. Goetghebeur; P. van Damme y G. Gheysen. 2005b. Molecular phylogeny and evolution of Caricaceae based on rDNA internal transcribed spacer (ITS) and chloroplast sequence data. Mol. Phylogenet. Evol. 37, 442-459.

Lloyd, G. y B.H. McCown. 1981. Woody Plant MediumA mineral nutrient formulation for microculture of woody plant species. HortScience 16, 453.

Murashige, T. y F. Skoog. 1962. A revised medium for rapid growth at bio-assays with tobacco tissue cultures. Physiol. Plant. 15, 473-497.
Nitsch J.P. y C. Nitsch. 1969. Haploid plants from pollen grains. Science 163, 85-87.

Muñoz, M. 1965. Síntomas de deficiencias nutricionales en plantas de papayo (Carica candamarcensis Hook). Trabajo de grado. Facultad de Agronomía, Universidad de Chile, Santiago.

Tennant, P., C. Gonsalves; K. Ling; M. Fitch; R. Manshardt; J. Slightom y D. Gonsalves. 1994. Differential protection against papaya ringspot virus isolates in coat protein gene transgenic papaya and classically cross-protected papaya. Phytopathol. 84, 1359-1366.

Tennant, P.; G. Fermin; M. Fitch; R. Manshardt; J. Slightom y D. Gonsalves. 2001. Papaya ringspot virus resistance of transgenic Rainbow and SunUp is affected by gene dosage, plant development, and coat protein homology. Eur. J. Plant Pathol. 107, 645-653.

Vélez D.; R. Armijos y M. Jordan. 2009. Germinación $\mathrm{y}$ desarrollo in vitro de embriones de Vasconcellea stipulata Badillo: tratamientos pre-germinativos y control de hiperhidricidad (en preparación). 